\title{
Behavior of Thermal Dissipation and Tensile Properties of Aluminum 4ACSR
}

\author{
Dinesh P \\ Department of Mechanical Engineering, \\ Sri Krishna Institute of Technology \\ Bengaluru-560090 Karnataka, India.
}

\author{
Dr. Prashanth Banakar \\ Principal, \\ Jain College of Engineering and Technology, \\ Hubballi-580031, Karnataka, India.
}

\begin{abstract}
The objective of this research was to gain a better understanding of thermally conductive and electrically insulating properties.

The utilization of thermal conductive polymeric composites is growing up, where the polymers filled with the thermally conductive fillers effectively dissipate heat. Thermally conductive particles filled polymer composites have advantages due to their easy process ability, low cost and durability to the corrosion.

The better understanding of tensile properties of epoxy resin composites reinforced with hardener, the effect of laminates has been investigated \& experimentation was performed to determine property data for material specifications, the laminates were obtained by hand layup process. The test ready specimens were subjected to tensile loads on Universal Testing machine. This research indicates that tensile strength is mainly dependent on the orientation \& thickness of laminated polymer composites.
\end{abstract}

Keywords-Epoxy resin, laminated polymer composites, Insulation, Aluminum 4ACSR

\section{INTRODUCTION}

Energy conservation has become major task to satisfy the energy need of world. Different methods are tried for conservation of energy. Thermal insulators play a big role in preventing losses of heat. Various types of insulating materials with sources from agricultural products \& its wastes, industrial wastes those have shown excellent insulating ability.

Aluminum Alloys are supplied in a very wide range of tempers with Non-heat treatable alloys - Alloys whose strength/mechanical properties are achieved by cold working (rolling, extruding, etc.). Sometimes called work hardening alloys, Temper is denoted by letter $\mathrm{H}$.

ACSR (Aluminium Conductor Steel Reinforced) Conventional conductors with steel core. It's a bimetallic conductor. The inner layers are composed by steel wires and the external layers are composed by hard-drawn aluminium. The steel wires guarantee high mechanical erformances.1350 is among the "EC" or "Electrical Conduction" Alloys due to it's high purity of $99.5 \%$ aluminum, $0.15 \% \mathrm{Si}, 0.4 \% \mathrm{Fe}, 0.05 \% \mathrm{Cu}, 0.05 \% \mathrm{Mn}, 0.01 \% \mathrm{Cr}$, $0.05 \% \mathrm{Zn}$ and others $0.03 \%$. Alloy 1350 is widely used in a number of electrical and other industries due to its conductivity and formability.
Teflon (polytetrafluoroethylene) is the du Pont trade name for the polymer made from tetrafluorethylene. The polymer has a linear chain structure of carbon atoms, to each of which is attached two fluorine atoms. It is capable of continuously withstanding operating temperatures in the range of 200 to $300^{\circ} \mathrm{C}$. It is insoluble and is attacked only by a few rarely occurring materials. Its electrical losses are low, and its volume and surface resistivity's are high. It has outstanding dielectric properties that remain stable with frequency and temperature. It resists ignition and does not promote the spread of flames. Teflon has a uniquely high bulk density.

- Excellent thermal and electrical insulation properties

- Low coefficient of friction

- Chemical resistant

Epoxy The primary reason for epoxy's popularity is its superb mechanical strength. Epoxy also has excellent resistance to chemicals. After setting, there is no worry of a chemical reaction that will weaken the seal. It also resists heat That resistance makes it ideal for electronics and electrical systems and other industrial applications.

It has excellent gap filling properties. Epoxy is resistant to cold, radiation, and steam. The superior performance of epoxy remains when exposed to adverse environmental conditions.

Epoxy sets fast and can easily stick to fingers. Before starting a job, be completely prepared. Epoxy stuck to fingers is difficult to remove. Epoxy glue is a two-part resin. The parts are the resin and a hardener that reacts, chemically, when mixed. They produce a strong bond that adheres to nearly any clean surface. The components do not set while in the tube with the cap in place. Therefore, epoxy has a long shelf-life. Epoxies set hard and fill gaps that add stiffness and strength to glued materials. Epoxy coatings are stain resistant, the cost of epoxy is economical and coating provides added safety.

\section{EXPERIMENTAL}
A. Materials
1) Aluminum 4ACSR
2) Mila Film
3) Teflon
4) Epoxy 


\section{B. Instrumental}

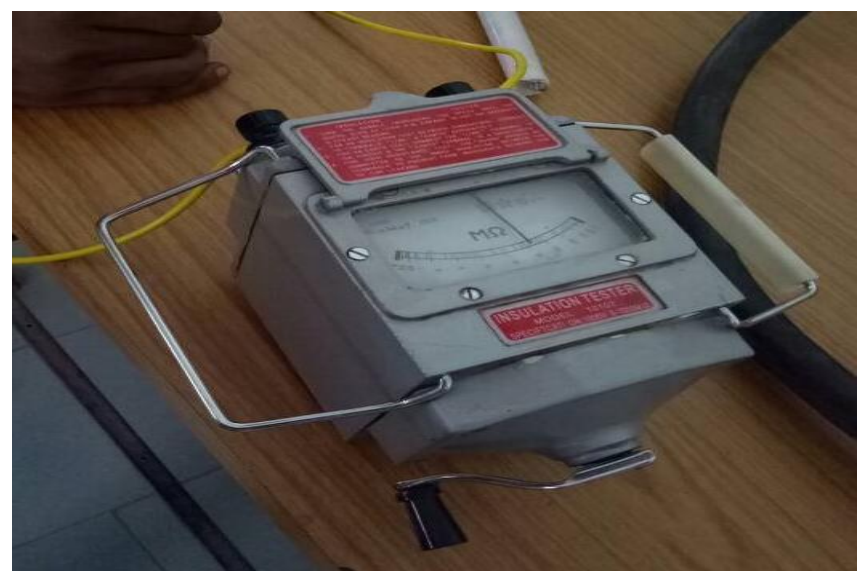

Fig 1: Insulation Tester or Megger

The Megger insulation tester is a small, portable instrument that gives you a direct reading of insulation resistance in ohms or mega ohms. For good insulation, the resistance usually reads in the mega ohms range.

\section{Sample Preparation}

Step1:

In any practical cases, before starting of operation there is some initial set up and some accessories needed. So we set all the external equipments at the operation time.

Taking all the required materials and scaling is necessary for those materials

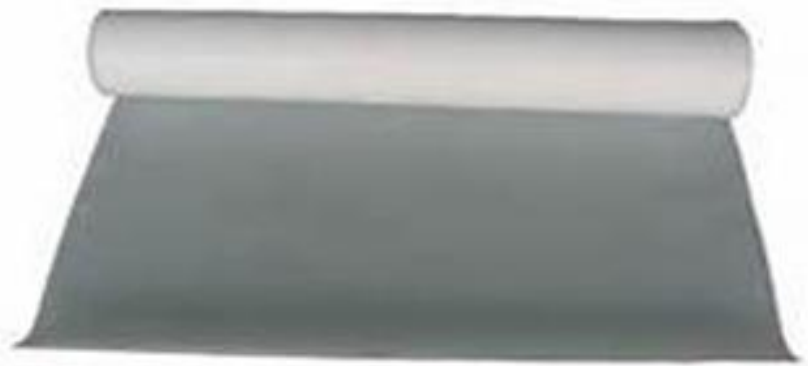

Fig 2: Teflon sheet material

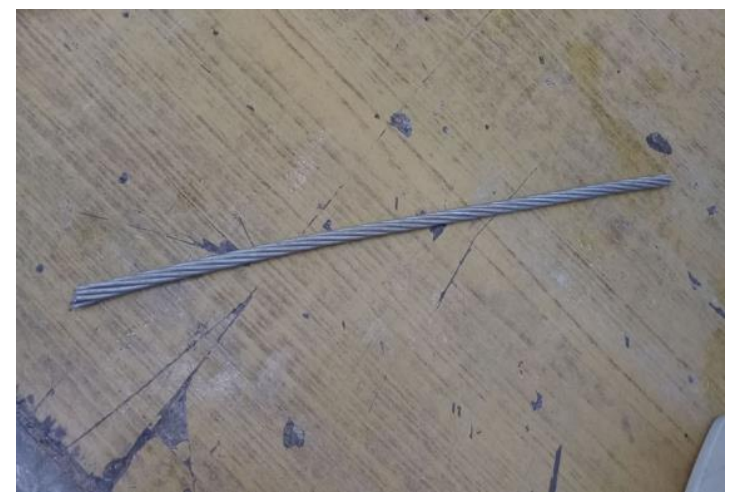

Fig 3: Aluminum wire

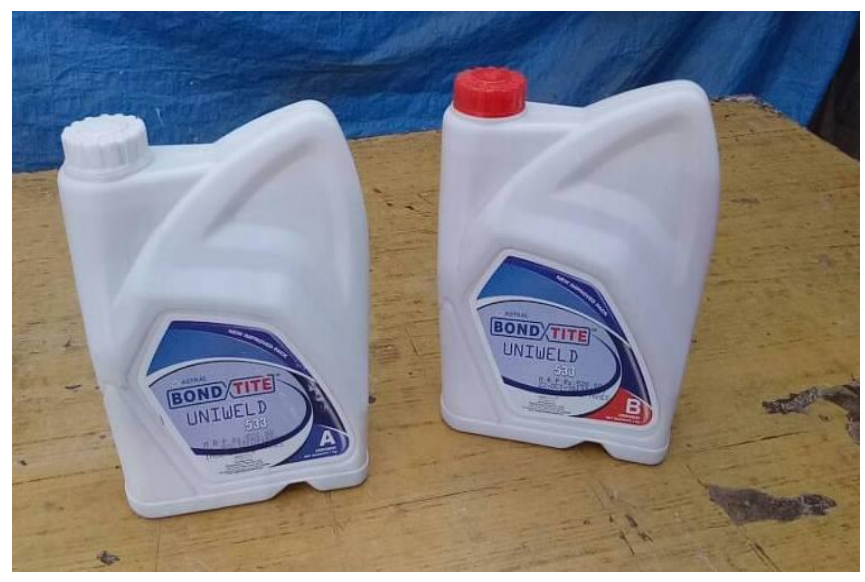

Fig4: Epoxy with hardener

Step2:

Completion of step 1, it required of some specific measurements for all materials. Measure the Teflon sheet for $10 \mathrm{~mm}$ diameter coating thickness and mix the epoxy resin with hardener in equal solutions.

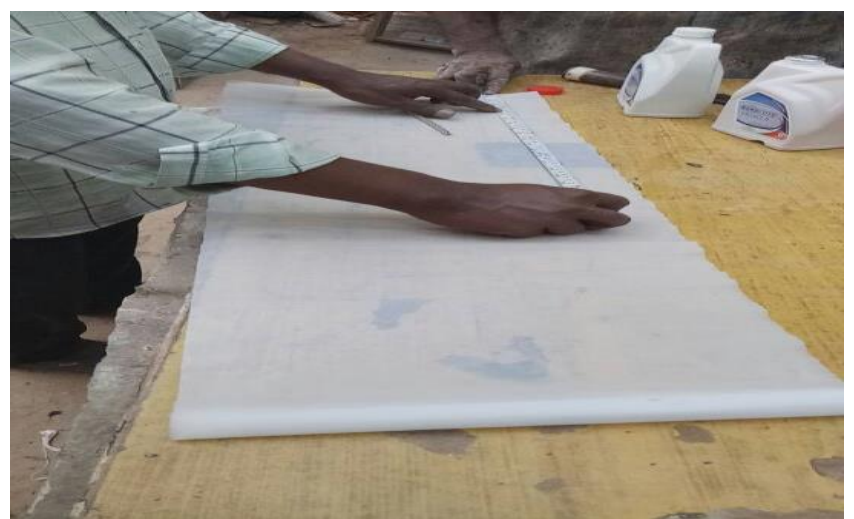

Fig 5

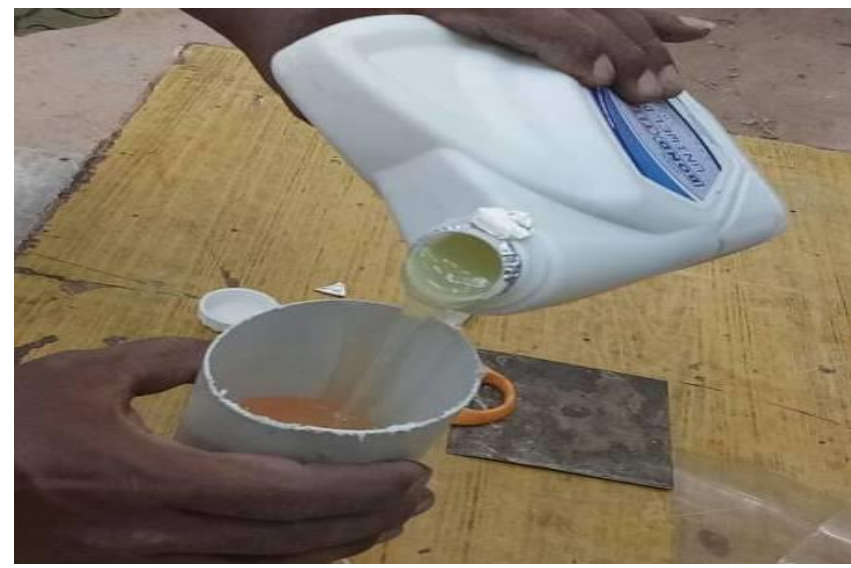

Fig 6 


\section{Step3:}

Take Teflon sheet and place it on the flat board. Spreading of epoxy resin which is mixed with hardener(bonding material) in equally on the Teflon sheet material.

Place the aluminium on the Teflon sheet and operation of spinning action done by manual process. After finishing the process Mila film is covered for certain time (approximately 36hrs).

All the corresponding figures shown below:

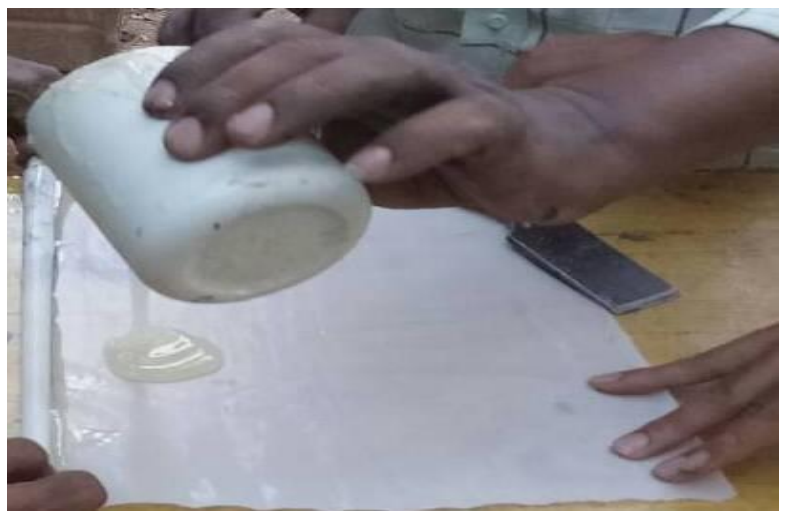

Fig 7

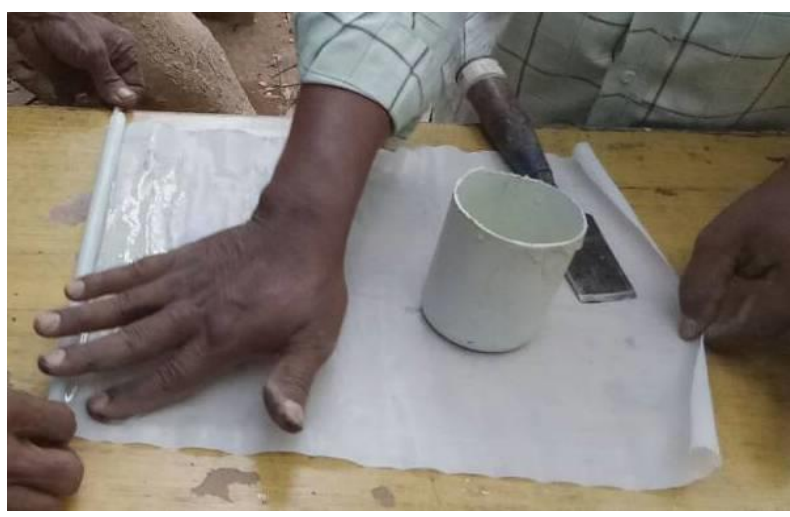

Fig 8

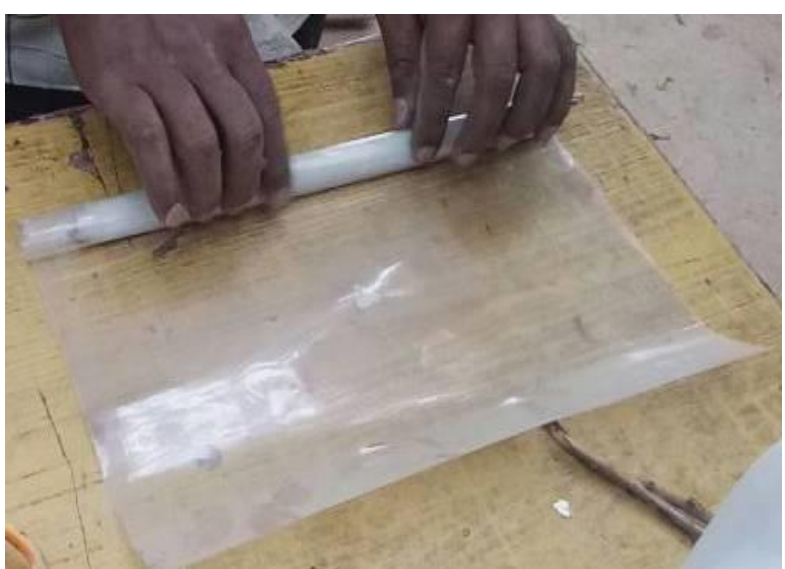

Fig 9

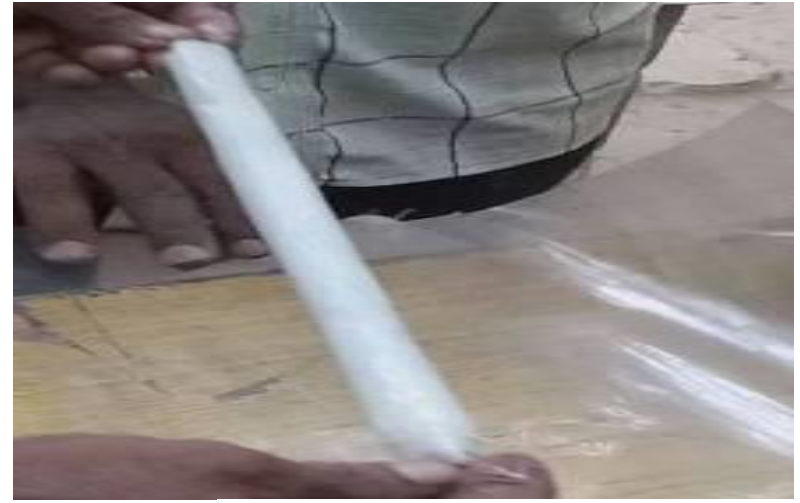

Fig 10

After completing the process, leave at least one day for rigidly fixed in natural atmosphere.

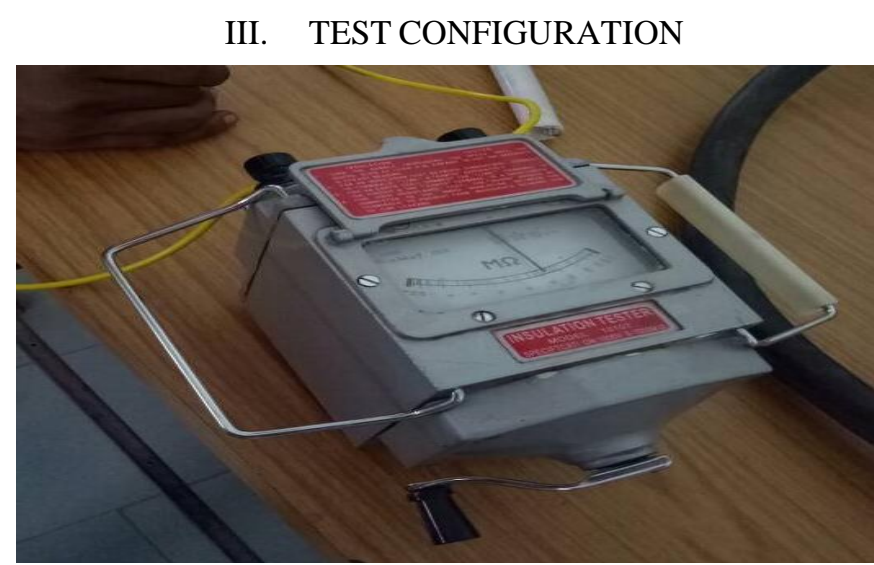

Fig 11

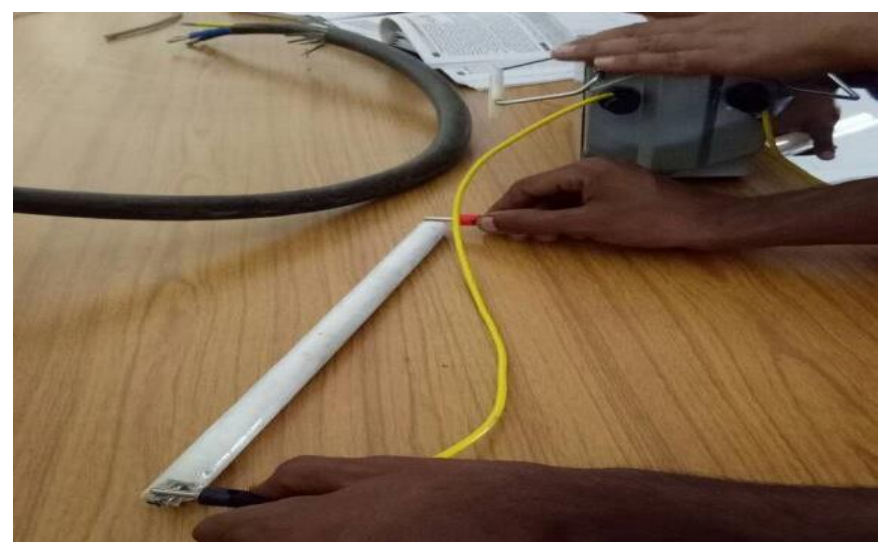

Fig 12

\section{CALCULATIONS}

$$
\mathrm{Ri}=\frac{\rho}{2 \pi l} \ln \frac{\mathrm{D}}{\mathrm{d}}
$$

$\mathrm{Ri}=$ Insulation Resistance

$\mathrm{d}=$ Core diameter

l=Specimen length

$\mathrm{D}=$ Diameter including, Insulation + Conductor core $=7.5 \times 108 \Omega \cdot \mathrm{m}$

Where $\mathrm{D}=\mathrm{d}+\mathrm{t}$ 


$$
\begin{aligned}
& \mathrm{Ri}=\frac{\rho}{2 \pi l} \ln \frac{\mathrm{D}}{\mathrm{d}} \\
& \text { 1] } \mathrm{Ri}=\quad \frac{7.5 \times 10^{8}}{2 \times \pi \times 15 \times 10^{-}} \\
& \mathrm{Ri}=780.5 \times 10^{6} \mathrm{M} \Omega \\
& \text { 2] } \mathrm{Ri}= \\
& \mathrm{Ri}=674.2 \times 10^{6} \mathrm{M} \Omega \\
& \text { 3] } \mathrm{Ri}=\quad \frac{7.5 \mathrm{x}}{2 \times \pi \times 1} \\
& \mathrm{Ri}=551.5 \times 10^{6} \mathrm{M} \Omega
\end{aligned}
$$

Before coating wire resistance- $2.7 \times 10^{-8} \mathrm{M} \Omega$

After coating wire resistance $-780 \mathrm{M} \Omega$

Coating thickness for $6 \mathrm{~mm}$ diameter of wire-10mm.

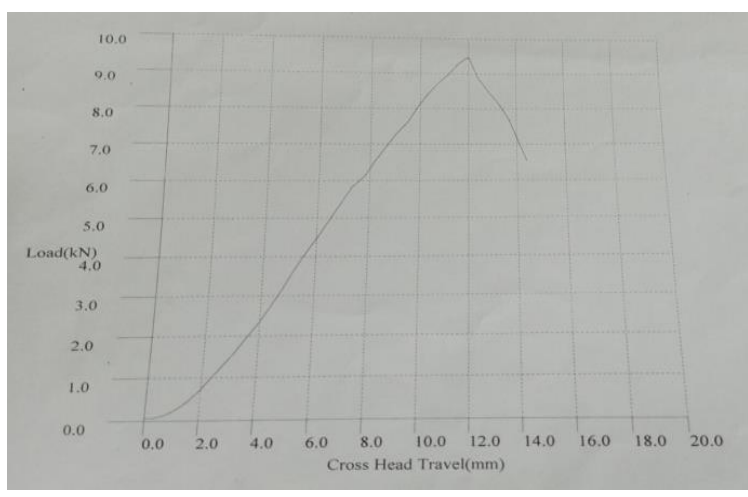

Fig 13: Load VS Cross Head Travel for Aluminium without coated material.

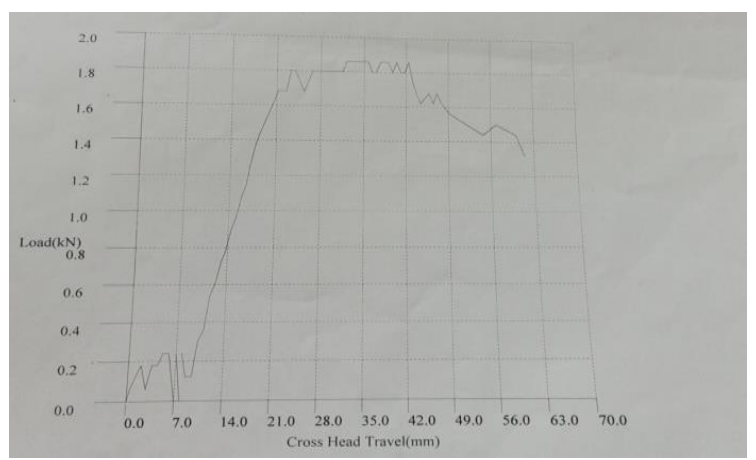

Fig 14: Load VS Cross Head Travel for Aluminium with coated material.

\section{RESULT AND DISCUSSION}

Description of the instrument: Conductivity of Aluminum 4ACSR/Aluminum Wire 4SSR Grade

Size: $6 \mathrm{~mm}$

Conductor: Aluminum

Insulation Size: $10 \mathrm{~mm}$

Insulation: Teflon coating with Epoxy
TABLE 1

\begin{tabular}{|l|l|l|l|l|l|}
\hline $\begin{array}{l}\text { Sl } \\
\text { No }\end{array}$ & $\begin{array}{l}\text { Temperature } \\
\text { set in }{ }^{\circ} \mathrm{C}\end{array}$ & $\begin{array}{l}\text { Readi ng } \\
\text { in }{ }^{\circ} \mathrm{C}\end{array}$ & $\begin{array}{l}\text { Test } \\
\text { Conditions }\end{array}$ & Status & Result \\
\hline 1 & 50 & 50.08 & 2 Hours & $\begin{array}{l}\text { No change in } \\
\text { Size or } \\
\text { Diameter }\end{array}$ & Positive \\
\hline 2 & 100 & 100.11 & 2 Hours & $\begin{array}{l}\text { No change in } \\
\text { Size or } \\
\text { Diameter }\end{array}$ & Positive \\
\hline
\end{tabular}

Conductivity of Aluminum 4ACSR/ Aluminum Wire 4SSR Grade of $16 \mathrm{~mm}$ which include insulation Teflon coating with Epoxy size of $10 \mathrm{~mm}$ which is kept at a temperature of $50^{\circ} \& 100^{\circ}$ for about 2 hours. The status no change in Size or Diameter.

From the above result analysis we conclude the result is Positive.

\section{CONCLUSIONS}

An experimental and theoretical work has been completed in this research. This theoretical and experimental investigation on thermal conductivity of aluminium filled epoxy composites have led to the following specific conclusions:

Successful fabrication of epoxy based composites filled with aluminium by hand-lay-up technique is possible.

Teflon is a very unique chemical in many ways. Its uniqueness stems from the way it was discovered and its chemical properties. The practical ways in which it can be used has led to being a part of many extraordinary things, is used as an insulation for communication cables, valves, seals, pipes.

The effect of tensile properties of epoxy resin composites reinforced with hardener has performed to determine property data for material specifications, Load VS Cross Head Travel for both Aluminium with and without coated material had a positive results for the laminates obtained by hand layup process. This research indicates that tensile strength is mainly dependent on the orientation \& thickness of laminated polymer composites.

\section{REFERENCES}

[1] Prashanth Banakar,Shivananda H, Niranjan H B "Influence of Fiber Orientation and Thickness on Tensile Properties of Laminated Polymer Composites" Int.J.Pure Appl.Sci.Technol. vol.9.2012/01/01.

[2] Devendra, K., and Rangaswami, T., "Evaluation of thermal properties of glass/ epoxy composites filled with different filler matrials", International Journal Of Computational Engineering Research, Vol 2, 2014, pp. 1708-1714.

[3] Ramver Singh, and Sharma P.K., "Effective thermal conductivity of metal filled polymer composite", Indian Journal Of Pure \& Applied Physics, Vol 49, 2011, pp. 112-116.

[4] Sonam Aggarwal, "Effective Thermal Conductivity of Epoxy Matrix Filled with Titania powder", Thesis, National Institute of technology, Rourkela, May, 2011.

[5] Khan, M.O., "Thermally conductive polymer composites for electronic packaging applications", Thesis, University of Toronto, 2012.

[6] M.M. Schwartz,Composite Materials: Properties, Nondestructive Testing and Repair, V.1, Prentice- Hall Inc., New Jersey, USA, 1997

[7] Journal of Material Science and Mechanical Engineering (JMSME) Print ISSN: 2393-9095; Online ISSN: 2393-9109; Volume 2, Number 8; April-June, 2015 pp. 34-36 (C) Krishi Sanskriti Publications http://www.krishisanskriti.org/jmsme.html 